\title{
Complex and novel determinants of empathy change in medical students
}

\author{
Gerald Sng Gui Ren ${ }^{1}$, Joshua Tung Yi Min ${ }^{1}$, Yeo Su Ping ${ }^{2}$, Lee Shuh Shing ${ }^{2}$, Ma Thin Mar Win ${ }^{3}$, \\ Hooi Shing Chuan ${ }^{1}$ and Dujeepa D. Samarasekera ${ }^{2}$ \\ ${ }^{1}$ Dean's Office, Yong Loo Lin School of Medicine, National University of Singapore, ${ }^{2}$ Centre for Medical Education, \\ Yong Loo Lin School of Medicine, National University of Singapore, and ${ }^{3}$ Biostatistics Unit, Yong Loo Lin School \\ of Medicine, National University of Singapore, Singapore
}

Purpose: Physician empathy is a core attribute in medical professionals, giving better patient outcomes. Medical school is an opportune time for building empathetic foundations. This study explores empathy change and focuses on contributory factors. Methods: We conducted a cross-sectional study involving 881 students (63\%) from Years 1 to 5 in a Singaporean medical school using the Jefferson Scale of Physician Empathy-Student version (JSPE-S) and a questionnaire investigating the relationship between reported and novel personal-social empathy determinants.

Results: Empathy declined significantly between preclinical and clinical years. Female and medical specialty interest respondents had higher scores than their counterparts. Despite strong internal consistency, factor analysis suggested that the JSPE model is not a perfect fit. Year 1 students had highest Perspective Taking scores and Year 2 students had highest Compassionate Care scores. High workload and inappropriate learning environments were the most relevant stressors. Time spent with family, arts, and community service correlated with higher empathy scores, whilst time spent with significant others and individual leisure correlated with lower scores. Thematic analysis revealed that the most common self-reported determinants were exposure to activity (community service) or socialisation, personal and family-related event as well as environment (high work-load).

Conclusion: While the empathy construct in multicultural Singapore is congruent with a Western model, important differences remain. A more subtle understanding of the heterogeneity of the medical student experience is important. A greater breadth of determinants of empathy, such as engagement in arts-related activities should be considered.

Key Words: Empathy, Medical students, Personal-social empathy determinants

\section{Introduction}

One of the main challenges of medical education at present is to develop a graduate competent in contextspecific as well as domain-independent skill-sets essential for effective future practice. Domain-independent skills sets such as building good doctor-patient relationships are essential for the success or failure of physicians' practices [1]. In addition, physician empathy (PE), or clinical empathy has been established to lead to better doctorpatient relationships and patient safety [2], and is a core attribute in medical professionals [3,4]. Empathy is a complex, multidimensional construct with four domainsEmotive, Moral, Cognitive, and Behavioural [5]. In the context of PE, this is the ability to understand mean-
Received: October 8, 2015 • Revised: December 12, 2015 • Accepted: December 14, 2015 Corresponding Author: Dujeepa D. Samarasekera (http://orcid.org/0000-0002-6916-6741) Centre for Medical Education, Yong Loo Lin School of Medicine, National University of Singapore, Level 11 Dean's Office, NUHS Tower Block, 1E, Kent Ridge Road, Singapore 119228 Tel: +65.65163760 Fax: +65.68721454 email: meddds@nus.edu.sg
Korean J Med Educ 2016 Mar; 28(1): 67-78. http://dx.doi.org/10.3946/kjme.2016.11 eISSN: 2005-7288

(C) The Korean Society of Medical Education. All rights reserved. This is an open-access article distributed under the terms of the Creative Commons Attribution Non-Commercial License (http:// creativecommons.org/licenses/by-nc/3.0/), which permits unrestricted non-commercial use, distribution, and reproduction in any medium, provided the original work is properly cited. 
ingfully the patient's situation, perspective, and feelings, as well as to communicate, and to act therapeutically on that understanding effectively with patients' consent and assistance [6].

Additionally, high levels of PE have been strongly suggested to correlate with positive health outcomes for the patient, both tangible [7,8] and intangible [9], greater patient satisfaction [10], and a stronger patient-physician relationship $[2,11,12]$. Hence, it is no surprise that the past years have seen robust discussion and research focusing largely on examining empathy changes and potential interventions in the training process of medical professionals [13]. Medical schools are a particular area of interest, as they represent a unique opportunity to build foundational skills in empathy that students may continue to build upon after graduation.

Unfortunately, the decline of empathy levels as medical students progress through their training is a well-documented trend that has been observed in many studies internationally [14], with reports from schools in locations from the United States, to Europe, to China [15]. However, these findings have been contested [16]. At the same time, other studies in contexts as varied as Japan [17], Iran [18], Ethiopia [19] and most recently, Portugal [20] have shown that, regardless, this is not necessarily a universal trend, perhaps due to different cultural contexts or students' educational backgrounds at admission [17,18]. However, the school in Singapore where the study was done represents a unique context, with a training model with influences from both the traditional British and American methods of training, whilst having cultural contexts similar to many other South and East Asian societies. This unique cultural context presents a great opportunity for further investigation.

Possible reasons for the decline of empathy have been elaborated on by Neumann et al., who proposed a "model of reasons" for the decline of empathy in medical students and residents as they progress through their training $[14,15]$. However, these reasons postulated focus on factors in and around medical training; no study has yet evaluated social and personal factors that may affect empathy change in medical students.

The study was therefore designed to firstly evaluate the validity and reliability of the Jefferson Scale of Physician Empathy-Student version (JSPE-S) and its associated model of empathy in a syncretic international context. Secondly, we will determine the differences between the empathy profile of Singaporean students and their overseas counterparts, as well as investigate specific causes behind factors previously associated with empathy decline, especially year of study, and to explore potential cultural differences. Lastly, we will identify and elaborate on novel factors that might contribute to changes of empathy in medical students.

\section{Subjects and methods}

\section{Participants}

Ethical approval was granted by the National University of Singapore Institutional Review Board (13-143). A cross-sectional and voluntary study was undertaken. The participants were medical students of all years of study (1 to 5) enrolled in the 5-year undergraduate medicine programme at the Yong Loo Lin School of Medicine. Eight hundred and eighty-one students participated in the study, representing $62.9 \%$ of the student population. Of these, 468 (53.7\%) identified themselves as females and $403(46.3 \%)$ as males.

\section{Instruments}

Two separate questionnaires were used: 
(1) JSPE-S, comprising of 20 items across three domains (perspective taking, compassionate care, and standing in patients' shoes) evaluated on a 7-point Likert scale. Age, gender, year of study, and prospective specialty choice were also collected. The original English version designed by Hojat et al. [21] was used. This tool was used as it has satisfactory psychometric properties [21], and has been validated in a number of different countries, most relevantly in China, Korea, and Japan [17,22,23]. It has shown good correlation with other measures of empathy [24,25], as well as with direct healthcare outcomes such as diabetes control [7,26].

(2) To augment understanding of the JSPE-S scores, we developed a new questionnaire to evaluate nontraditional social and personal factors that might contribute to changes of empathy. This had a combination of numerical data on the hours spent and activities of students in different areas (studying, individual leisure activities, group leisure activities, with family, with significant other, in the arts, on religious activities, on community service), a 6-point Likert-scaled selfreported evaluation of structural and personal stressors that may be relevant to empathy change, based partially on the "model of reasons" reported by Neumann [14], and an open-ended question inviting students to suggest additional reasons for empathy change. The complete questionnaire is shown in the Appendix 1.

\section{Procedures}

The two questionnaires were distributed to the participants at the beginning of the 2013/2014 academic year, and were completed individually and anonymously.

\section{Statistical analyses}

Item-total score correlations were calculated from the individual item responses on the JSPE-S. Next, factor analysis was done with principal component factor extraction and varimax rotation with Kaiser normalization to determine the underlying factor structure. Additionally, analysis of the scores for each factors between years of study was undertaken. Cronbach's $\alpha$ was calculated to evaluate the internal consistency reliability of the tool. Finally, to more robustly demonstrate construct validity, confirmatory factor analyses were done.

The JSPE-S scores of respondents were analysed by year of study with analysis of variance with Bonferroni correction. Additional analysis of the self-reported evaluation of factors against year of study was conducted. Gender and specialty choice were analysed with two-tailed t-tests. Further analysis was done to analyse the effect of hours spent in different activities and participation in community service activities on JSPE score, using linear regression analysis. Finally, opennded responses were coded and analysed to identify the major themes. Statistical analysis was done using SPSS version 13.0 (SPSS Inc., Chicago, USA) and SPSS AMOS.

\section{Results}

\section{Response rate}

\section{1) Reliability}

The Cronbach coefficient $\alpha$ was 0.83 , which indicates an acceptable internal consistency.

\section{2) Factor analysis}

A Kaiser-Meyer-Olkin analysis yielded a high index of 0.91. Bartlett's test for sphericity was also highly significant $\left(X_{(190)}^{2}=5,321 ; \mathrm{p}=0.00\right)$.

Exploratory factor analysis revealed four factors, accounting for $51.40 \%$ of the variance. However, the fourth factor was explained only by one item (Q18), and accounted for only $\sim 5 \%$ of the variance. We therefore 
restricted factor extraction to the original three-factor model of the JSPE-S. As seen in Table 1, this model confirmed the three-factor model described by Hojat with two caveats-Question 18 had poor factor loading scores in all domains, whilst Question 19 had a low factor loading score, despite falling unequivocally into the appropriate domain.

A confirmatory factor analysis showed a goodness-offit of 0.947 and a root mean square error of approximation of $<0.05$, further confirming the validity of the factor structure of the JSPE [27].

\section{3) Descriptive statistics and analysis}

The descriptive statistics broken down by year of study, gender, and specialty choice (where applicable) are shown in Table 2. The overall mean was 112.18 (standard deviation, 11.381).

As shown in Table 2, there were no statistically significant differences in scores between adjacent years of students in contrast to many studies $[15,28,29]$ which showed a statistically significant decline in empathy

Table 1. Factor Structure of the Jefferson Scale of Physician Empathy-Student Version

\begin{tabular}{|c|c|c|c|c|}
\hline \multirow{2}{*}{$\begin{array}{l}\text { Item } \\
\text { No. }\end{array}$} & \multirow{2}{*}{ Question } & \multicolumn{3}{|c|}{ Factor } \\
\hline & & 1 & 2 & 3 \\
\hline 16 & $\begin{array}{l}\text { Physicians'understanding of the emotional status of their patients, as well as that of their } \\
\text { families is one important component of the physician-patient relationship }\end{array}$ & 0.731 & - & - \\
\hline 10 & $\begin{array}{l}\text { Patients value a physician's understanding of their feelings which is therapeutic in its own } \\
\text { right }\end{array}$ & 0.723 & - & - \\
\hline 4 & $\begin{array}{l}\text { Understanding body language is as important as verbal communication in physician-patient } \\
\text { relationships }\end{array}$ & 0.697 & - & - \\
\hline 20 & I believe that empathy is an important therapeutic factor in medical treatment & 0.677 & - & - \\
\hline 9 & Physicians should try to stand in their patients' shoes when providing care to them & 0.672 & - & - \\
\hline 2 & Patients feel better when their physicians understand their feelings & 0.658 & - & - \\
\hline 17 & Physicians should try to think like their patients in order to render better car & 0.627 & - & - \\
\hline 13 & $\begin{array}{l}\text { Physicians should try to understand what is going on in their patients' minds by paying attention } \\
\text { to their nonverbal cues and body language }\end{array}$ & 0.617 & - & - \\
\hline 15 & Empathy is a therapeutic skill without which the physician's success is limited & 0.567 & - & - \\
\hline 5 & A physician's sense of humor contributes to a better clinical outcome & 0.418 & - & - \\
\hline 8 & Attentiveness to patients' personal experiences does not influence treatment outcomes & - & 0.705 & - \\
\hline 7 & Attention to patients' emotions is not important in history taking & - & 0.675 & - \\
\hline 11 & $\begin{array}{l}\text { Patients' illnesses can be cured only by medical or surgical treatment; therefore, physicians' } \\
\text { emotional ties with their patients do not have a significant influence in medical or surgical } \\
\text { treatment }\end{array}$ & - & 0.643 & - \\
\hline 1 & $\begin{array}{l}\text { Physicians' understanding of their patients' feelings and the feeling of their patients' families } \\
\text { does not influence medical or surgical treatment }\end{array}$ & - & 0.610 & - \\
\hline 14 & I believe that emotion has no place in the treatment of medical illness & - & 0.523 & - \\
\hline 12 & $\begin{array}{l}\text { Asking patients about what is happening in their personal lives is not helpful in understanding } \\
\text { their physical complaints }\end{array}$ & - & 0.523 & - \\
\hline 19 & I do not enjoy reading nonmedical literature or the arts & & 0.353 & - \\
\hline 18 & $\begin{array}{l}\text { Physicians should not allow themselves to be influenced by strong personal bonds between } \\
\text { their patients and their family members }\end{array}$ & -0.121 & 0.156 & 0.107 \\
\hline 3 & It is a difficult for a physician to view things from patients' perspectives & - & - & 0.874 \\
\hline 6 & Because people are different, it is difficult to see things from patients' perspectives & - & - & 0.873 \\
\hline
\end{tabular}

Exploratory factor analysis reveals three factors conforming to the original model of the Jefferson Scale of Physician Empathy. Factors 1 , 2, and 3 are Perspective Taking, Compassionate Care, and Standing in Patient's Shoes, respectively. Items are scored on a 7-point Likert scale. Items $1,3,6,7,8,11,12,14,18$, and 19 are reverse-scored. 
Table 2. Descriptive Statistics across Year of Study, Gender, and Specialty Choice

\begin{tabular}{lcccc}
\hline & No. & Mean & Unadjusted p-value & Adjusted p-value \\
\hline Year & & & & \\
1 & 265 & 114.30 & $<0.001$ & $<0.001$ \\
2 & 197 & 114.07 & $<0.001$ & 0.002 \\
3 & 177 & 111.71 & 0.096 & 0.070 \\
4 & 112 & 108.98 & 1.000 & 0.942 \\
5 & 130 & 108.37 & Reference & Reference \\
Total & 881 & 112.18 & - & - \\
Gender & & & & 0.216 \\
Female & 468 & 113.57 & $<0.001$ & Reference \\
Male & 403 & 110.57 & Reference & \\
Specialty choice & & & & 0.018 \\
Medical & 270 & 113.62 & 0.012 & Reference \\
Surgical & 216 & 110.86 & Reference & \\
\hline
\end{tabular}

Table 3. Empathy Factor Scores by Year of Study

\begin{tabular}{|c|c|c|c|c|c|c|c|}
\hline \multirow{2}{*}{ Factor } & \multicolumn{5}{|c|}{ Year } & \multirow{2}{*}{ Avg. } & \multirow{2}{*}{ Sig. } \\
\hline & 1 & 2 & 3 & 4 & 5 & & \\
\hline Perspective taking & 61.17 & 60.10 & 58.29 & 56.59 & 56.72 & 59.11 & $<0.001$ \\
\hline Compassionate care & 44.66 & 45.44 & 44.88 & 44.06 & 43.23 & 44.60 & 0.007 \\
\hline Standing in patients' shoes & 8.50 & 8.53 & 8.55 & 8.33 & 8.42 & 8.48 & 0.947 \\
\hline
\end{tabular}

Fig. 1. Reported Relevance of Suggested Stressors on a 6-Point Likert Scale Ranging from 1 (Not at All Relevant) to 6 (Extremely Relevant)

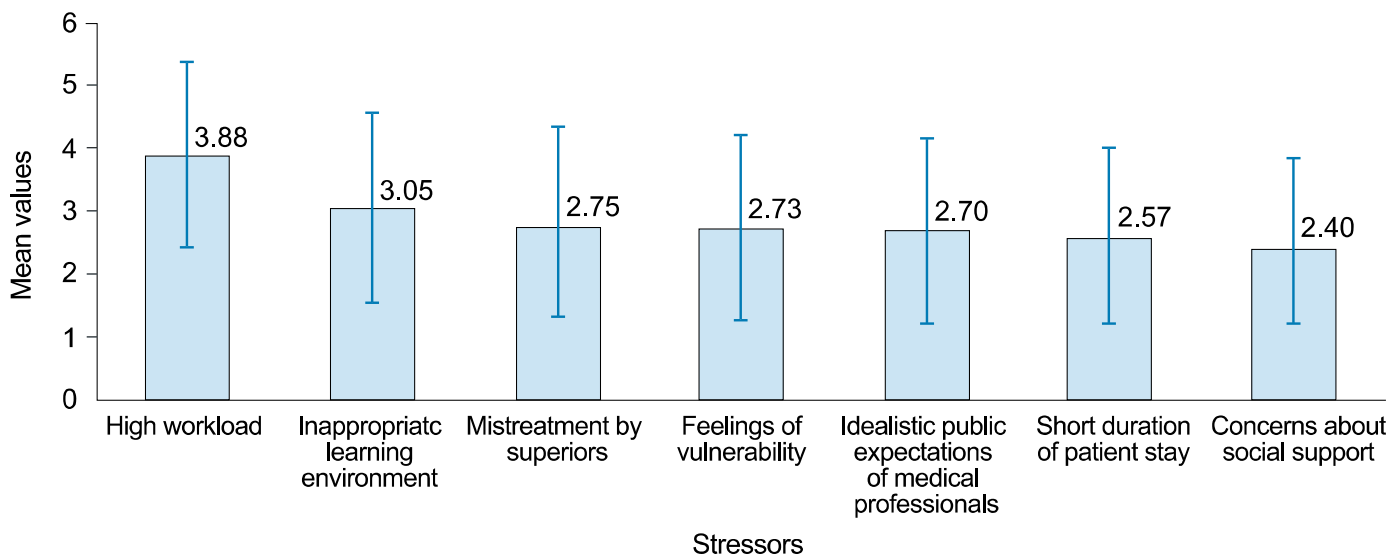

Mean values and error bars representing 1 standard deviation are shown.

scores in between the 2nd and 3rd years of medical school. However, a statistically significant difference was noted between 1st year students (learning is mostly preclinical subjects) and students from the 3rd, 4th, and 5th years (training in clinical years). A significant difference in empathy scores was also noted between male and female participants $(\mathrm{p}<0.001)$, and between participants intending to pursue a medical speciality compared to those intending to do a surgical speciality $(\mathrm{p}=0.012)$. However, no significant difference was seen 
between those intending to pursue clinical and nonclinical disciplines.

Analysis of the scores from the three factors in the JSPE showed that 1st Year students had the highest Perspective Taking scores, 2nd Year students had the highest Compassionate Care scores, and there was no significant difference in Standing in Patients' Shoes scores across all 5 years (Table 3).

\section{4) Analysis of questionnaire}

The relevance of suggested stressors is reported in Fig. 1. High workload is perceived by students to be the most relevant stressor, although responses were in general equivocal. Analysis of responses based on year of study revealed that Year 2 students were least affected by high workload $(\mathrm{p}<0.001)$, had the least concerns about learning environment $(\mathrm{p}<0.001)$ and mistreatment by superiors $(p<0.001)$. There was a significant difference between years regarding social support problems $(\mathrm{p}=0.019)$. Year 1 students had the most concerns in this area, whilst Year 4 students had the least.

We observed that more time spent with family $(\beta=$ 0.062, $\mathrm{p}=0.037)$ and the arts $(\beta=0.342, \mathrm{p}=0.001)$

Table 4. Representative Samples of Qualitative Responses

\begin{tabular}{|c|c|}
\hline Category & Quotations \\
\hline Exposure (activity) & $\begin{array}{l}\text { (1) Negative change: } \\
\text { "Harder to empathise when we are so hogged down by our workload" and "seeing them as part of } \\
\text { work has decreased my ability to empathise with them." } \\
\text { "Desensitisation over time and at times harsh and unappreciative patients may make us empathise less." } \\
\text { "The long working hours have made me more indifferent and "sian" [a feeling of ennui] such that I can } \\
\text { only think about getting the job done and not how others feel." } \\
\text { (2) Positive change (predominantly in Years } 1 \text { and } 3 \text { students): } \\
\text { "Yes, it has changed since I started my clinical posting. Actually interacting with them and learning about } \\
\text { their problem other than the medicinal aspects has been eye-opening." } \\
\text { "Exposure to patients in the wards [*..] enhanced my ability to empathise with patients and the difficulties } \\
\text { they face in different aspects of life." } \\
\text { "Involvement in community projects such as volunteering at a children's centre has sharpened my sensitivity } \\
\text { to the needs of others and I believe that I am very blessed to have gained exposure to people with } \\
\text { different medical needs to increase my capacity for empathy." } \\
\text { "A life value built up from the community involvement projects." }\end{array}$ \\
\hline $\begin{array}{l}\text { Exposure } \\
\text { (socialization) }\end{array}$ & $\begin{array}{l}\text { "Being in the wards allowed me to interact with patient in person and develop communication skills. Also, } \\
\text { being able to know their plight through first hand interaction has allowed me to empathise with them more." } \\
\text { "Communicate with real patients." }\end{array}$ \\
\hline $\begin{array}{l}\text { Personal and family } \\
\text { related event }\end{array}$ & $\begin{array}{l}\text { "When you experience something not as a doctor but as a family member, where you have to spend more } \\
\text { hours with that 'patient', everything is different. I begin to wonder why the doctor taking care of my family } \\
\text { member is brushing his problems aside. I have learnt to listen, to look at things from a nonmedical professional } \\
\text { point of view. Realised the power of listening. That sometimes all people need is a listening ear." } \\
\text { "[l am] slightly more able to empathise after meeting more different people from different backgrounds [in } \\
\text { the army]." } \\
\text { "Being an infantry officer cadet, there were many instances outfield when the unfavourable conditions rendered } \\
\text { me weak and vulnerable, much like a patient. Having undergone some form of suffering, I am able to empathise } \\
\text { with people better." } \\
\text { "Father was diagnosed with hepatitis B." }\end{array}$ \\
\hline Religion & $\begin{array}{l}\text { "I become more religious." } \\
\text { "Improved by religious journeying." }\end{array}$ \\
\hline Maturity & "Growing older as a person who understands more." \\
\hline
\end{tabular}


correlated with a higher empathy score, whilst more time spent in individual leisure hours $(\beta=-0.096, \mathrm{p}=0.013)$ and with significant others $(\beta=-0.096, \mathrm{p}=0.026)$ correlated with a lower empathy score. Additionally, a greater number of community service projects undertaken correlated with a higher empathy score $(\beta=0.77, \mathrm{p}<$ 0.001). The study results also showed that time spent on studying, religious activities and group leisure activities had no effect on empathy scores.

$30.8 \%$ of respondents felt that their ability to empathise had changed in the last 3 months and there was an increase of students in Years 4 and 5 showing deterioration in empathy mainly due to environmental factors such as high workload and inappropriate role model shown by colleagues in workplace. The most common explanations for the increase in empathy were exposure to either activity or socialisation, personal or family related events, religion and maturity. Representative quotations from their responses in each category can be found in Table 4.

\section{Discussion}

The internal consistency and factor analysis values of the JSPE are globally comparable [14], representing its usefulness and reliability to the unique Singaporean context. However, we suggest that the East Asian concept of empathy as a construct may be subtly different from that in America or the West. The poor factor loading for Question 18 ("Physicians should not allow themselves to be influenced by strong personal bonds between their patients and their family members") indicates a lower discriminatory value, likely due to the family-centric approach to medical decision-making prevalent in Asian societies. Additionally, the relatively low score for Question 19 ("I do not enjoy reading nonmedical literature or the arts"), also noted in other East Asian studies [23], suggests a lower emphasis on literature and the arts in these cultures. The JSPE may require modification to accurately represent the different cultural construct of empathy in East Asian societies.

The empathy profile of Singaporean students is similar to that conventionally reported, with a significant decline in the "transition period" from preclinical to clinical years, and stronger empathy in females. Anecdotal stereotypes of medical and surgical personalities were also analysed for the first time in this study. Despite the significant difference between the two noted, it is of course important to refrain from reinforcing stereotypes of surgeons as uncaring and physicians as emotional.

New learning environments, patient contact and burnout experienced during the clinical years are likely to explain the differences observed between the preclinical and clinical years, with students perceiving high workload and inappropriate learning environments as the most relevant stressors in their medical education. It is easy to understand how "seeing patients as part of work" may quickly lead to "only thinking about getting the job done," negatively impacting empathy towards patients.

However, the decline of empathy on entering the clinical years here is not as precipitous as reported elsewhere. Empathy is a complex construct its constituent components behave heterogeneously and therefore bear individual study. Compassionate Care improves from Year 1 to 2 but declines thereafter. We believe that Year 2 students, who report being least affected by workload, learning environments and superior mistreatment, are least likely to succumb to "seeing patients as part of work," and therefore gain greater emotional capacity for compassionate care towards patients. Perspective Taking is highest in Year 1 and thereafter declines. Year 1 students report the highest level of 
concerns about social support, which may place them in a unique position to understand the vulnerabilities faced by patients themselves, albeit generally of a different sort. The ability to [Stand] in Patients' Shoes does not appear to change throughout the years, possibly as undergraduate students do not have the life experience to fully appreciate personal, financial and family difficulties that often come with being a patient.

These individual factors and their relative weights should be investigated further. Nevertheless, it is important to consider that when efforts are made to address declining empathy levels, interventions should be tailored to each year's specific needs; blanket interventions may not be effective across all levels if they target factors that are less affected in individual years.

Part of the second aim of the study was to compare the scores of Singaporean students with those reported elsewhere. The scores of Singapore students compare favourably with that of other East Asian centres, being higher than their counterparts from China, Japan, and Korea. However, their scores were lower than those from the United States. This occupancy of a middle ground in relation to these countries is not surprising when viewed from a sociohistoric perspective. Singapore's long colonial heritage which shaped the education system as well as the Asian roots could have facilitated the confluence of Asian and Western cultures. Moreover, English remains the language of instruction and daily communication, thus eliminating possible linguistic or semantic uncertainties in understanding the concept of empathy. Within the school, equal emphasis is placed on the competing priorities of service and academic excellence, which may also help to preserve relatively higher empathy scores. As it is an undergraduate programme, the relative youth and lack of life experience of the students could account for the lower scores than their U.S. graduate counterparts.
This complex empathy construct is also affected by the environment in which the student lives outside of school and clinically-focused pursuits and should therefore be informed by the student's personal-social milieu. To that end, we report novel findings that time spent on certain activities affects empathy scores.

Interestingly, there is a contrasting effect of time with significant others (definition left open to interpretation by respondents; likely their girlfriends/boyfriends or close friends) compared against time with family, despite how both can be considered positive and healthy personal relationships for students. A possible explanation might be that family interactions are more nurturing and allow more inclusivity, whereas interactions with one's significant other are more individualistic and exclusive, an explanation which is supported by our finding that individual leisure activity is also related to an empathy decline. Perhaps the larger family unit also lends itself to more experiences of major life events, such as illnesses or death. This could also be a cultural effect, as described by studies on individualism and collectivism in different cultural context [30,31,32].

That time spent in the arts correlates with higher empathy scores is unsurprising, with various reasons proposed from the practical, such as the development of effective communication skills or media, to the prosaic, such as a greater understanding of the "human condition" [33].

The strong positive correlation between community service activities and empathy scores also highlights the importance of engaging medical students in these activities [30]. Students suggested that first-hand exposures to the underprivileged, disadvantaged, the young or the elderly through both self-initiated and curricular community service programmes may have increased their capacity to empathise. These are therefore useful interventions to promote empathy. However, the effect may 
be mitigated by an inherent selection bias - perhaps more empathetic individuals would choose to do more community service. Moreover, participation in community service activities may often form an informal part of medical school admissions, further increasing this selection bias.

Other potential areas for intervention are suggested by students' comments that empathy decline during the transition period is mitigated by positive formative clinical experiences. Many felt that the first-hand interaction/communication with the patients provided them with the opportunity to gain a better understanding of the patients' perspectives, plights or the difficulties and realities facing them. Consequently, some began to reflect on the values of empathy, while others developed higher sensitivity towards the patients, which could have raised their ability to empathise. Most of the qualitative comments are from students in the initial year of their respective phases (preclinical and clinical). This raises the possibility that early patient contact at the beginning of their phases of training positively affects empathy development. We also found that experiences acquired during compulsory military service before matriculation seemed to have a key role in instilling a sense of empathy among the male students. Finally, several respondents remarked that meeting people with contrasting backgrounds helped them to understand how those from different social circles think, feel and live.

Limitations of this study are worth noting. The JSPE is a self-reported tool that does not directly assess practical components of clinical empathy. Also, students were surveyed at the beginning of their school year, while different time periods have been used in other studies. Next, a responder bias may be present as participation was entirely voluntary, although we believe this limitation is mitigated by the high overall response rate of $62.9 \%$. Finally, a cross-sectional study cannot take into account inter-batch variability in empathy profiles as a result of changes in curriculum, current affairs or even simply having been born 5 years apart.

To sum, this study suggests further development of the JSPE in the East Asian context may be useful. It illustrates a unique perspective on empathy in medical school in a new context, whereby Singaporean students may represent a middle-ground in their empathy development, as a result of the social and cultural syncretism between Asia and the West described earlier. Interventions aimed at fostering empathy must target specific individual factors within the empathy construct. A more complete look at factors affecting empathy beyond the curriculum and in students' personal life may be required in further research. In considering students' development as empathetic physicians, it is important to recognise that they first have to be empathetic persons, shaped by attitudes, beliefs and experiences that go far beyond the confines of their formal education. It may be that the best interventions improve empathy by supporting students as persons, and from thence allowing the other values including empathy, to flow.

Acknowledgements: The authors thank Dr Chan Yiong Huak from the National University of Singapore for his guidance in the statistical methods and tools used in this study.

Funding: The study was funded by a Teaching Award Grant from the Ministry of Education, Singapore.

Conflicts of interest: None.

\section{References}

1. Heijke H, Meng C. Discipline-specific and academic competencies of the higher educated: their value in the 
labour market and their acquisition in education. Maastricht, The Netherlands: Research Centre for Education and the Labour Market (ROA), Faculty of Economics and Business Administration, Maastricht University; 2006.

2. Riess H, Kelley JM, Bailey RW, Dunn EJ, Phillips M. Empathy training for resident physicians: a randomized controlled trial of a neuroscience-informed curriculum. J Gen Intern Med 2012; 27: 1280-1286.

3. Veloski JJ, Hojat M. Measuring specific elements of professionalism: empathy, teamwork, and lifelong learning. In: Stern DT, ed. Measuring medical professionalism. Oxford, UK: Oxford University Press; 2005. p 117-145.

4. Glaser KM, Markham FW, Adler HM, McManus PR, Hojat M. Relationships between scores on the Jefferson Scale of physician empathy, patient perceptions of physician empathy, and humanistic approaches to patient care: a validity study. Med Sci Monit 2007; 13: CR291-CR294.

5. Morse JM, Anderson G, Bottorff JL, Yonge O, O'Brien B, Solberg SM, McIlveen KH. Exploring empathy: a conceptual fit for nursing practice? Image J Nurs Sch 1992; 24: 273-280.

6. Mercer SW, Reynolds WJ. Empathy and quality of care. Br J Gen Pract 2002; 52 Suppl: S9-S12.

7. Hojat M, Louis DZ, Markham FW, Wender R, Rabinowitz C, Gonnella JS. Physicians' empathy and clinical outcomes for diabetic patients. Acad Med 2011; 86: 359-364.

8. Neumann M, Scheffer C, Tauschel D, Lutz G, Wirtz M, Edelhauser F. Physician empathy: definition, outcomerelevance and its measurement in patient care and medical education. GMS Z Med Ausbild 2012; 29: Docll.

9. Neumann M, Bensing J, Mercer S, Ernstmann N, Ommen O, Pfaff H. Analyzing the "nature" and "specific effectiveness" of clinical empathy: a theoretical overview and contribution towards a theory-based research agenda. Patient Educ Couns 2009; 74: 339-346.

10. Kim SS, Kaplowitz S, Johnston MV. The effects of physician empathy on patient satisfaction and compliance. Eval Health Prof 2004; 27: 237-251.

11. Chaudhry HJ, Rhyne J, Cain FE, Young A, Crane M, Bush F. Maintenance of licensure: protecting the public, promoting quality health Care. J Med Regul 2010; 96: 13-20.

12. Hickson GB, Federspiel CF, Pichert JW, Miller CS, Gauld-Jaeger J, Bost P. Patient complaints and malpractice risk. JAMA 2002; 287: 2951-2957.

13. Krasner MS, Epstein RM, Beckman H, Suchman AL, Chapman B, Mooney CJ, Quill TE. Association of an educational program in mindful communication with burnout, empathy, and attitudes among primary care physicians. JAMA 2009; 302: 1284-1293.

14. Neumann M, Edelhäuser F, Tauschel D, Fischer MR, Wirtz M, Woopen C, Haramati A, Scheffer C. Empathy decline and its reasons: a systematic review of studies with medical students and residents. Acad Med 2011; 86: 996-1009.

15. Hojat M, Vergare MJ, Maxwell K, Brainard G, Herrine SK, Isenberg GA, Veloski J, Gonnella JS. The devil is in the third year: a longitudinal study of erosion of empathy in medical school. Acad Med 2009; 84: 1182-1191.

16. Colliver JA, Conlee MJ, Verhulst SJ, Dorsey JK. Reports of the decline of empathy during medical education are greatly exaggerated: a reexamination of the research. Acad Med 2010; 85: 588-593.

17. Kataoka HU, Koide N, Ochi K, Hojat M, Gonnella JS. Measurement of empathy among Japanese medical students: psychometrics and score differences by gender and level of medical education. Acad Med 2009; 84: 1192-1197.

18. Rahimi-Madiseh M, Tavakol M, Dennick R, Nasiri J. Empathy in Iranian medical students: a preliminary 
psychometric analysis and differences by gender and year of medical school. Med Teach 2010; 32: e471-e478.

19. Dehning S, Girma E, Gasperi S, Meyer S, Tesfaye M, Siebeck M. Comparative cross-sectional study of empathy among first year and final year medical students in Jimma University, Ethiopia: steady state of the heart and opening of the eyes. BMC Med Educ 2012; 12: 34.

20. Costa P, Magalhães E, Costa MJ. A latent growth model suggests that empathy of medical students does not decline over time. Adv Health Sci Educ Theory Pract 2013; 18: 509-522.

21. Hojat M, Mangione S, Nasca TJ, et al. The Jefferson Scale of Physician Empathy: development and preliminary psychometric data. Educ Psychol Meas 2001; 61: 349-365.

22. Wen D, Ma X, Li H, Liu Z, Xian B, Liu Y. Empathy in Chinese medical students: psychometric characteristics and differences by gender and year of medical education. BMC Med Educ 2013; 13: 130.

23. Roh MS, Hahm BJ, Lee DH, Suh DH. Evaluation of empathy among Korean medical students: a crosssectional study using the Korean Version of the Jefferson Scale of Physician Empathy. Teach Learn Med 2010; 22: 167-171

24. Hojat M, Mangione S, Kane GC, Gonnella JS. Relationships between scores of the Jefferson Scale of Physician Empathy (JSPE) and the Interpersonal Reactivity Index (IRI). Med Teach 2005; 27: 625-628.

25. Pedersen R. Empirical research on empathy in medicine: a critical review. Patient Educ Couns 2009; 76: 307-322.
26. Del Canale S, Louis DZ, Maio V, Wang X, Rossi G, Hojat M, Gonnella JS. The relationship between physician empathy and disease complications: an empirical study of primary care physicians and their diabetic patients in Parma, Italy. Acad Med 2012; 87: 1243-1249.

27. Browne MW, Cudeck R. Alternative ways of assessing model fit. In: Bollen KA, Long JS, eds. Testing structural equations models. Newbury Park, USA: Sage; 1993. p 136-162.

28. Chen D, Lew R, Hershman W, Orlander J. A crosssectional measurement of medical student empathy. J Gen Intern Med 2007; 22: 1434-1438.

29. Newton BW, Barber L, Clardy J, Cleveland E, O'Sullivan P. Is there hardening of the heart during medical school? Acad Med 2008; 83: 244-249.

30. Markus HR, Kitayama S. Culture and the self: implications for cognition, emotion, and motivation. Psychol Rev 1991; 98: 224-253.

31. Kashima Y, Yamaguchi S, Kim U, Choi SC, Gelfand MJ, Yuki M. Culture, gender, and self: a perspective from individualism-collectivism research. J Pers Soc Psychol 1995; 69: 925-937.

32. Triandis HC. Individualism-collectivism and personality. J Pers 2001; 69: 907-924.

33. Hojat M, Gonnella JS, Mangione S, Nasca TJ, Magee M. Physician empathy in medical education and practice: experience with the Jefferson Scale of Physician Empathy. Semin Integr Med 2003; 1: 25-41. 
Appendix 1.

EMPATHY PROFILING OF STUDENTS IN YLLSOM

SN:Xxx

Gender:

Likely Specialty Choice (if applicable):

1. Within the last academic year, how many community service projects/activities were you involved in?

2. Are you involved in any long-term community service projects/activities?

Yes/No

3. If you are, what is the frequency and duration of your involvement? (e.g., two hours, twice a month)

4. On average, how many hours a week (outside of school hours) do you spend:

\begin{tabular}{l|l}
\hline Studying & With family \\
\hline Individual leisure activities (e.g., surfing the web) & Group leisure activities (e.g., team sports) \\
\hline In the arts (e.g., theatre, music, dance, literature etc.) & With your significant other (if applicable) \\
\hline On religious activities lif applicable) & - \\
\hline
\end{tabular}

5. How relevant are the following factors to your medical school experience, or how much have they affected your ability to connect with patients? On a scale of 1 (not at all) - 6 (totally relevant)

\begin{tabular}{l|l}
\hline Feeling vulnerable & Social support problems \\
\hline High workload & Short length of patient stay \\
\hline Unsuitable learning environments & $\begin{array}{l}\text { Over-idealised views of the medical profession in the } \\
\text { media/public }\end{array}$ \\
\hline Inadequacy or mistreatment by superiors/mentors & - \\
\hline
\end{tabular}

6. Have you experienced any significant personal events in the past 5 years?

Imajor life events include: serious illness or death of close relatives, serious personal physical or mental illness, family problems including divorce, being a victim of crime, pregnancy/abortion, episodes of serious financial hardship or any other traumatic life event; marriage/engagement, starting a new relationship, outstanding personal achievements/awards)

Yes

No

7. Do you think your ability to empathize has changed from 3 months ago? If yes, why? 